\title{
Gérard de Nerval, Euvres complètes, J.-N. Illouz (dir.), t. IX, Les Illuminés
}

\section{Lise Sabourin}

\section{Q OpenEdition}

10 Journals

\section{Édition électronique}

URL : http://journals.openedition.org/studifrancesi/10009

DOI : 10.4000/studifrancesi. 10009

ISSN : 2427-5856

Éditeur

Rosenberg \& Sellier

\section{Édition imprimée}

Date de publication : 1 août 2017

Pagination : 381

ISSN : 0039-2944

\section{Référence électronique}

Lise Sabourin, «Gérard de Nerval, EEuvres complètes, J.-N. Illouz (dir.), t. IX, Les Illuminés », Studi Francesi [En ligne], 182 (LXI | II) | 2017, mis en ligne le 01 août 2017, consulté le 13 janvier 2021. URL : http:// journals.openedition.org/studifrancesi/10009; DOI : https://doi.org/10.4000/studifrancesi.10009

Ce document a été généré automatiquement le 13 janvier 2021.

\section{(c) (i) (9)}

Studi Francesi è distribuita con Licenza Creative Commons Attribuzione - Non commerciale - Non opere derivate 4.0 Internazionale. 


\title{
Gérard de Nerval, Euvres complètes, J.-N. Illouz (dir.), t. IX, Les Illuminés
}

\author{
Lise Sabourin
}

\section{RÉFÉRENCE}

GÉRARD DE NERVAL, Euvres complètes, sous la direction de Jean-Nicolas Illouz, t. IX, Les

Illuminés, édition de Jacques-Rémi Dahan, Paris, Classiques Garnier, 2015, 458 pp.

1 Ces Illuminés de Nerval, moins connus que Les Filles du Feu, pourraient cependant bien être aussi des «fils du Feu», en hétérodoxes rédempteurs qu'ils veulent être au fil de l'histoire depuis la Renaissance. Nerval a en effet rassemblé en avril 1852 six «récits et portraits» déjà publiés isolément, en leur accolant un bref «avant-propos» intitulé «La bibliothèque de mon oncle» (pp. 41-42). Il réunit en fait les destinées de six opposants au pouvoir religieux, philosophique et politique dans lesquels se projette subrepticement le narrateur.

«Le roi de Bicêtre ( $\mathrm{xvI}^{\mathrm{e}}$ siècle)» (pp. 43-62), aliéné d'un asile fondé en fait seulement sous Louis XIV, est Spifame, imprimeur d'un recueil apocryphe d'édits d'Henri II, ce «meilleur roi de France» dont il se croit le double pour lui annoncer son destin tragique.

3 L'«Histoire de l'abbé de Bucquoy (XVII ${ }^{\mathrm{e}}$ siècle)» (pp. 63-119) conte les aventures picaresques, d'emprisonnements en évasions, de cet «espèce de fou», aristocrate défroqué, parent de l'Angélique des Filles du Feu, qui voulut s'opposer à l'arbitraire et l'oppression par une vie «toujours errante et pérégrinante» comme celle de Nerval.

«Les Confidences de Nicolas (XVIII ${ }^{\mathrm{e}}$ siècle)» (pp. 121-265) sont celles de Restif de la Bretonne, dont Nerval, au prix d'une enquête vraiment scientifique, retrace la vie désordonnée, gommant seulement l'érotomanie de ce «Hibou noctambule, ce piéton de Paris, le passionné de théâtre et le soupirant des jolies actrices» (p. 17) qui lui ressemble tant. 
5 Toujours dans ce XVIII ${ }^{\mathrm{e}}$ siècle qui lui apparaît comme le tournant vers ces «précurseurs du socialisme» (comme l'indiquait un sous-titre présent seulement en couverture), Nerval présente ensuite «Cazotte» (pp. 267-324), «un rêveur, un mystique, un magnétiseur» (p. 21), dont les prédictions et l'étude des phénomènes du sommeil le fascinent.

6 «Cagliostro» (pp. 325-344) assure le lien théosophique entre Templiers, francmaçonnerie, Réforme et Lumières, pour unir par-delà les époques jansénisme, martinisme, swedenborgisme et ces «llluminés de Bavière», disciples de Weishaupt, auxquels Nerval a sans doute emprunté son titre.

7 Enfin, «Quintus Aucler» (pp. 345-384), ce mystique révolutionnaire, auteur de La Thréicie.

8 En appendice (pp. 385-406) figurent «Le Diable rouge» (pp. 387-393), «Les Prophètes rouges» (pp. 395-406) que sont Buchez, Lamennais, Mickiewicz et Towiansky, Considerant, Pierre Leroux et Proudhon.

9 Jacques-Rémi Dahan explicite très bien dans son introduction (pp. 7-36) toutes les implications de ces textes qu'il annote soigneusement et fournit dans un dossier critique (pp. 407-425) les articles d'accueil, de juin 1852 à juillet 1853, sous les plumes de Cherbuliez, des Goncourt, d'Asselineau, Bell, Janin, d'un Anglais anonyme, de Barbey et de Limayrac, outre bibliographie (primaire et secondaire) et index nominum. 